\title{
Liberia's Political Economy: An Examination of Public Institutional Quality (Rule of Law, Democratic Accountability, and State Authority) Based on Citizens' Ethnic, Residence, and Gender Status by Stephen H. Gobewole A REVIEW
}

\author{
Dr. Rajeshkumar Acharya \\ Gujarat University
}

Stephen H Gobewole in his book "Liberia's Political Economy" (2016) discusses Liberia's history and ties it to a new study of Liberia's current political and social situation to understand the failure of the African country to develop broad-based entrepreneurship or a diverse, healthy economy.

The author in the book has explored how government corruption that arose from kinship and patrimonial practices created pubic institutional weakness. To understand this he has relied on public perception of public institutional weakness. The author has assessed an Afrobarometer study (a study that measured the citizens' perceptions of quality of public institutional weakness based on their ethnic, residence and gender status) to reveal that the demographic characteristics in the study and quantitative approach validated how there was weakness in Liberia's rule of law, state authority and democratic accountability. The author interprets the underlying cause of the findings in the book by concluding that "the nation's public institutional weakness stems from patronage practices, hiring bureaucrats, securing political office for offspring, and awarding jobs to supporters, that prevents the development of a modern (strong) state with a system of meritocracy" which explains the poor economic performance of the country. The author has brilliantly links the above cultural, political and economic variables to comment on the economic performance and growth of Liberia.

The book argues that modern practices (such as such as resource extraction, liberal economic policies (privatization), corruption in the government and wealth disparity due to historical colonialism prevents the economic growth. The author argues in favour of instituting policies linking all the research and analysis conducted in the book to formalize the property regime in Liberia and enact protectionist policies to encourage the growth of domestic industries. The author has put the onus of development on the government saying, "The Liberian government should be the primary investor in its nation's economic transformation. This objective" the author says "can be accomplished by enacting appropriate policies and subsidizing domestic firms to engage in new innovations, industrial processes, and technological equipment". The book is meticulous, introspective and has connected the right variables resulting in the author giving pragmatic strategy and a brilliant starting point for Liberia's government to achieve economic growth by creating stronger industries which, in turn, will lead to higher levels of education and improved standards of living of the people and overall economic growth. 